\title{
Subsídios do \\ Instituto Florestal \\ para o Projeto FLORAM
}

EQUIPE DO IF-CPRN,

SECRETARIA DO MEIO AMBIENTE, SP

\section{Introdução}

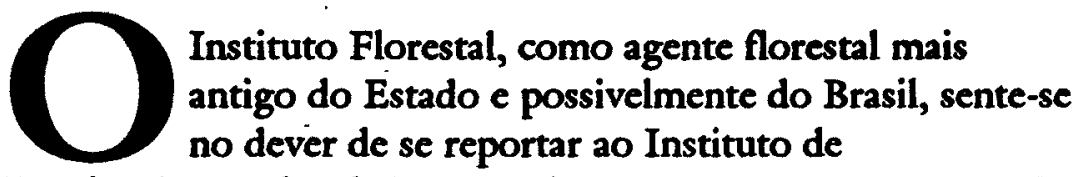

Estudos Avançados da USP, onde se encontra em gestação o Projeto FLORAM, no sentido de apresentar sua contribuição, já que para isto foi solicitado pelo digno Diretor desta organizaçáo, Dr. Jacques Marcovitch, no "workshop" realizado no dia 21 de junho, na sede da Secretaria do Meio Ambiente, em resposta à fala de um dos nossos pesquisadores.

Enaltecemos o discurso, que começa a difundir a preocupaçáo do Instituto de Estudos Avançados, fazendo votos de êxito para que se enriqueça da energia de todos os setores da sociedade brasileira, no intuito de que as barreiras burocráticas e econômicas sejam vencidas ao nível do país e do exterior e a fim de que este ideal consiga se tornar realidade.

É de se louvar a iniciativa do conceituado Instituto em abordar não só em âmbito nacional, mas planetário, temática de tal magnitude e nos sentimos de certa forma amparados, no sentido de continuarmos perseguindo o ideal que há mais de ứm século vimos propalando neste Estado, conforme atestam os Anexos 1 e 2. Com o mesmo espírito, em 1981 o Instituto Florestal do Estado de Sáo Paulo encaminhou ao Instituto Brasileiro de Desenvolvimento Florestal - IBDF o documento "Elenco de Medidas para Promover o Reflorestamento e a Conservaçáo dos Recursos Florestais em Sáo Paulo" (Anexo 3), com o intuito de provocar a reativação do reflorestamento no Estado. 
Em 1984, apresentou ao Governo do Estado a "Proposta de Política Florestal para o Estado de Sáo Paulo - Plano Emergencial" (Anexo 4) que, dentro das limitaçóes regionais e orçamentárias, tentou também conduzir o assunto no mesmo rumo hoje perseguido pelo Projeto FLORAM.

Conforme ficou patente pela fala de nosso representante no mencionado "workshop", a Instituição possui inquietaçóes com relação à conduçăo do processo ao nível do Estado de Sáo Paulo e muitas delas poderiam ser extrapoladas para o âmbito nacional, apreensōes estas que gostaríamos de passar ao grupo de estudos, como forma de contribuiçáo de nosso Instituto face ao enfrentamento que teve durante todos estes anos com a realidade florestal.

\section{Ponderações}

Algumas dúvidas se nos apresentam, ainda, com relação ao dimensionamento do Projeto FLORAM em nível nacional:

- O que levou à definição da área de 20 milhóes de hectares?

- O enfoque fundamental foi o da demanda atual das indústrias?

- E quanto à demanda futura?

- No orçamento previsto para os reflorestamentos protetivos, estariam incluídos também os recursos para a implantaçáo efetiva das Unidades de Conservaçăo federais, estaduais e municipais já criadas?

- Haverá meios financeiros para demarcação discriminatória, desapropriaçáo, recursos humanos e materiais para fiscalizaçáo e manejo dessas áreas?

- Como seria o sistema de fiscalizaçáo para controlar as açóes propostas?

Nossa preocupação, no entanto, se concentra em dois pontos básicos, que poderiam ser negativos sob o ponto de vista do desenvolvimento social:

\section{Conseqüencias ambientais que viriam na esteira do reflorestamento}

As explanações até agora difundidas pelo Projeto FLORAM não dão indício dos mecanismos que seriam adotados para seu controle. Em projeto de tamanha envergadura, a abrangência planetária, que leva a encarar o problema ambiental sob a ótica da escala do "efeito 
estufa", pode incorrer no pecado de olvidar-se dos ajustes à realidade fática do dia-a-dia.

Aliás, no "Zoneamento Econômico Florestal do Estado" (Anexo 5), onde as distâncias entre a visão macro e a micro estavam menos afastadas que no Projeto FLORAM, incorreu-se em distorçăo ao incluir toda a Região Administrativa de Sorocaba entre as "Áreas Prioritárias ao Reflorestamento", sem levar em consideração que este fenômeno traria, na esteira das consequiências, a atraçáo de indústrias ligadas ao setor papeleiro, que săo altamente poluidoras. A conseqüência foi a luta da sociedade civil, na década de 70 , contra a instalaçăo da Braskraft na área de influência do Rio Paranapanema, a única bacia ainda năo poluída na época.

Por outro lado, os estudos desenvolvidos por pesquisador do Instituto Florestal para a Regiāo Administrativa de Ribeirão Preto, no período de 1962 a 1984 (Anexo 6), dáo conta de que os reflorestamentos incentivados foram mais devastadores que o próprio Pró-Álcool, tăo condenado sob o ponto de vista ambiental.

Face ao avanço indiscriminado da agricultura, as florestas brasileiras vêm sendo destruídas rapidamente com perda de material genético de qualidade superior. A biodiversidade nas espécies florestais é uma defesa da natureza contra pragas, moléstias e condiçóes adversas. A seleção natural, agindo sobre essa variabilidade genética, tem como conseqüência a evoluçáo. A falta dessa biodiversidade é fator contra o plantio clonal em silvicultura. Quem incursiona neste campo corre o risco de perder tudo, a menos que lance mão de medidas como a mistura de clones.

O plantio clonal é um dos caminhos trilhados de maneira prática, hoje em dia, em várias empresas nacionais. O melhoramento genético é, em todos os países, fundamentalmente baseado no emprego do máximo de biodiversidade, através de plantios de populaçóes-base e a seleçáo de indivíduos com características fenotípicas desejáveis, propagação vegetativa, instalaçáo de pomares clonais de primeira geração e de gerações mais avançadas.

\section{Conseqüências fundiárias e econômicas}

Apesar do Projeto FLORAM abrigar a idéia da implantação do reflorestamento em pequenas e médias propriedades, o que foi ressaltado durante a fala do Dr. Werner Zulauf no "workshop", gostaríamos de lembrar que os reflorestamentos incentivados, com início na década de 60 , também tiveram esta preocupaçáo, inclusive 
contemplando-a com os instrumentos legais necessários. Estes instrumentos, no entanto, nāo foram suficientes para fazer frente aos "lobbies" do capital.

Para năo se iludir de que foram coisas do tempo da "Ditadura", basta comparar os preços de exportação de celulose em relaçăo aos preços da madeira pagos pelas indústrias aos agricultores no período, inclusive após a Nova República (Gráfico 1).

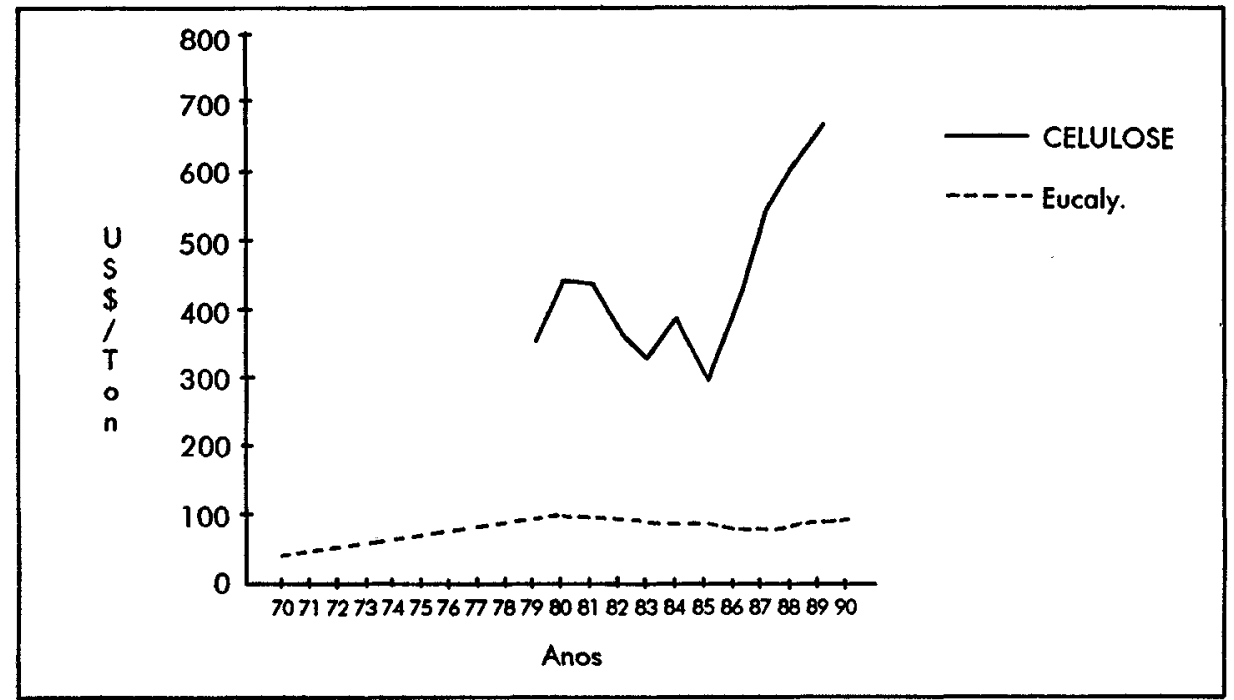

Gráfico 1 - Preços da celulose (FOB) e custo da madeira (CIF, em US\$/m3 st. sem casca) para a produçăo de 1 ton. de celulose

O Gráfico 2 mostra a posição ocupada pelo Brasil, em relação a outros países, quanto ao custo da madeira (fibra curta e longa) destinada ao fabrico da celulose.

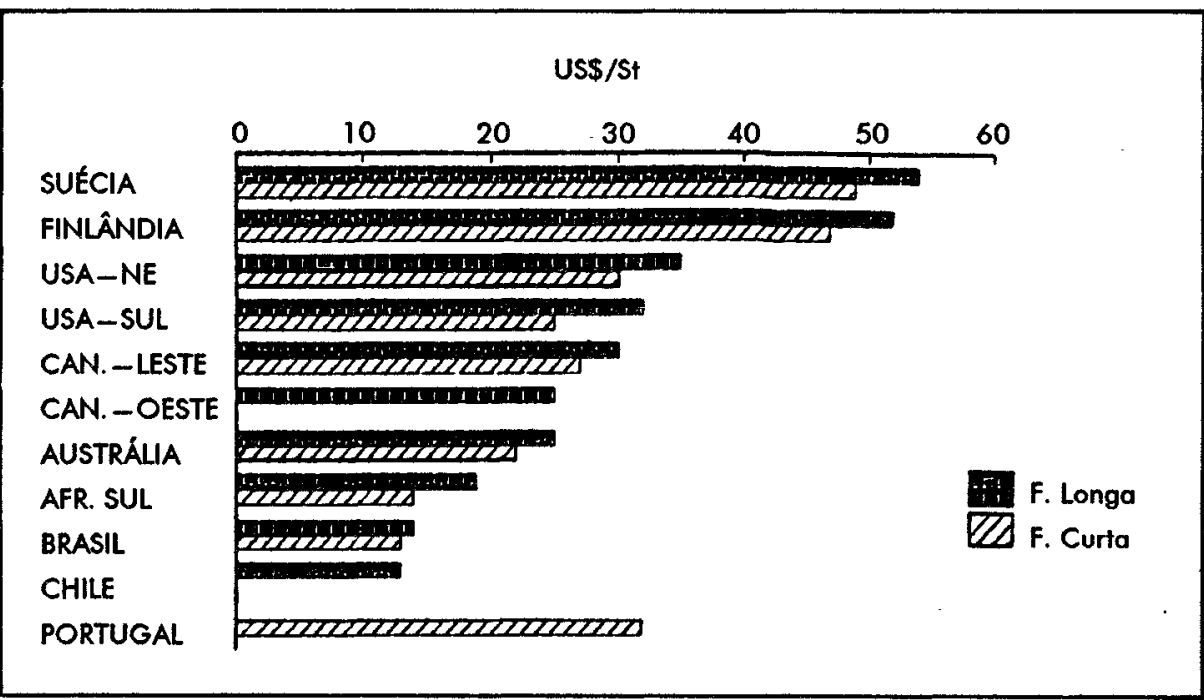

Gráfico 2 - Posiçāo brasileira do custo das madeiras de pinus e eucalipto na esfera internacional (Preços referentes ao $4^{\circ}$ trimestre de 1986 , em US\$ $/ \mathrm{m} 3$ st. sem casca) 
$\mathrm{Na}$ Época, não houve o cuidado de se criar a estrutura necessária para que as açóes previstas na legislaçáo se concretizassem. Ao contrário, a estrutura de extensáo florestal no Estado de São Paulo foi totalmente desarticulada no período.

Posteriormente, no período de 1980 a 1983, o Instituto Florestal liderou, no Estado, o "Programa de Reflorestamento em Pequenos e Médios Imóveis Rurais" - REPEMIR. Através desta experiência (Anexo 7), nosso Instituto, agora, mesmo sem as atribuiçóes de um órgão de extensão, detectou que houve reação positiva por parte dos agricultores frente ao programa. Curiosamente, ficou evidenciada a maior procura por espécies que náo vinham de encontro aos programas visados pela produçáo de papel e celulose; os investidores deram preferência às essências voltadas a usos mais nobres da madeira, como o Eucalyptus citriodora, em detrimento das de crescimento mais rápido, mas com madeira de qualidade inferior.

Ficou também evidenciado que programas dessa natureza só alcançam sucesso quando há disponibilidade de mudas de boa qualidade na época da implantaçäo e assistência técnica na fase pré e pós-plantio, demonstrando a necessidade de uma estrutura adequada de apoio e extensão florestal.

Um dos méritos dos reflorestamentos em pequenos e médios imb́veis rurais é o da sua pulverizaçáo em pequenos maciços florestais, minimizando os impactos ambientais e, conseqüentemente, a propagaçáo de doenças e pragas, facilitando, por outro lado, o atendimento do mercado local de madeira.

Em contrapartida, é oportuno alertar, no rol das estratégias preconizadas para os plantios industriais - representados por reflorestamentos clonais de elevada produtividade: os riscos de ocorrência de doenças e pragas florestais podem se suceder a níveis alarmantes, em razáo das perdas da variabilidade genética, de resistência vertical ou horizontal, sem contar com outros agravantes que afetam a biodiversidade da fauna pela eliminaçáo do sub-bosque, abrigo de muitas populaçóes naturais, controladoras de pragas e doenças.

\section{Contribuiçóes para a evoluçăo do Projeto FLORAM}

O Anexo 8 contém o programa de atividades e pesquisas em desenvolvimento em nossa Instituiçăo.

Dentre os estudos e açóes desenvolvidos e em andamento no Instituto 
Florestal, julgamos de importância imediata para a evoluçáo do Projeto FLORAM as seguintes contribuiçóes:

a) O "Macrozoneamento das Terras da Regiáo do Rio Ribeira de Iguape, SP" (Anexo 9), que analisa o problema florestal em um contexto mais amplo, face às demais atividades da regiáo, dá idểa de como o Instituto Florestal poderia subsidiar o Projeto FLORAM quando os estudos descerem ao nîvel de regionalização. A proposta do referido estudo partiu deste Instituto em 1977 e, apesar de todos os entraves políticos e burocráticos, a filosofia original pôde ser, em parte, recuperada em 1988, quando foi viabilizado.

b) Ainda no nível de uso e ocupaçáo do solo, as áreas críticas em processo de degradação por ação antrópica vêm sendo estudadas pelo Instituto Florestal, considerando os fatores físicos, climáticos e biológicos somados aos fatores antrópicos para a proposição de alternativas de prevenção e correção (Anexo 10).

c) Os estudos de hidrologia florestal, que vêm sendo desenvolvidos no Núcleo Cunha do Parque Estadual da Serra do Mar e na Estação Experimental de Mogi Guaçu (Anexo 11), objetivam subsidiar o manejo e monitoramento de bacias hidrográficas visando a produção qualitativa e quantitativa de água. Vàle destacar que a extrapolaçăo da experiência para outras localidades terá efeito multiplicador, ampliando a possibilidade de recuperação e preservaçäo de outros mananciais.

d) A Instituição possui em seu quadro, também, pesquisadores que vêm se dedicando às questóes relacionadas com a recomposição e o manejo para regeneração natural de florestas nativas. A publicação "Reflorestamento Heterogêneo com Essências Indígenas" (Anexo 11) bem exemplifica este tipo de açáo em área degradada do município de Cosmópolis - SP, assim como a "Regeneração Natural de Mata Ciliar na Estação Ecológica de Bauru" (no prelo), que exemplifica o segundo caso.

e) Visando florestas de produção, o Instituto Florestal vem desenvolvendo estudos de melhoramento genético florestal com espécies selecionadas de coníferas e folhosas, exóticas e nativas, objetivando o aumento da produtividade, por área, das florestas. Estes estudos, por ora, compreendem a conservação genética destas essências, instalaçăo de populações-base, seleção de matrizes, instalaçáo de 66 procedências e progênies, formação e manejo de pomares, produçáo de sementes melhoradas e intercâmbio 
tecnológico com empresas e instituiçóes de pesquisa. O Anexo 13 dá idéia da amplitude de espécies e procedências que vêm sendo trabalhadas pelo Instituto Florestal visando florestas de produção.

Na área de Pinus, nove espécies e variedades estáo sendo trabalhadas e os pomares clonais, de primeira geração, já se encontram em produção, com ganho genético em torno de $10 \%$. Na área de Eucaliptus, sete espécies estão sendo trabalhadas com objetivo de produção de madeira para serraria e energia. As espécies em estudo estáo com suas populaçóes-base implantadas è, algumas, já em fase de seleção fenotípica.

O Programa de "Melhoramento Genético" do Instituto Florestal é formado pelos seguintes subprogramas:

1) Pinus Tropicais - cujas espécies e variedades prioritárias são $P$ inus caribaea var. hondurensis, $P$. caribaea var. caribaea, $P$. caribaea var. babamensis, $P$. oocarpa, $P$. kesiya e P. patula tecunumanii.

A biodiversidade nas espécies florestais é uma defesa da natureza contra pragas, moléstias e condições adversas.
2) Pinus Subtropicais - cujas espécies e variedades prioritárias são: Pinus elliottii var. elliostii, $P$. taeda e $P$. maximinoi.

3) Eucalyptus spp. - cujas espécies e variedades prioritárias são: Eucalyptus citriodora, E. tereticornis, E. camaldulensis, E. urophylla, E. clocziana, E. resiniferae $E$. pilularis.

4) Essências Nativas - cujas espécies prioritárias para os trabalhos de conservaçăo genética através de populaçóes-base são: pinheiro-brasileiro (Araucaria angustiofolia), óleo de copaíba (Copaifera langsdorfii), guaritá (Astronium graveolens), timburi (Enterolobium contortisiliquum), pessegueiro-bravo (Prunus myrtifolia), cambaru (Dipteryx alata), amendoim (Pterogyne nitens), aroeira (Astronium urundeuva), jacarandá-paulista (Machaerium villosum), guarucaia (Peltophcrum dubium), jequitibá-rosa (Cariniana legaitis), pau-d'alho (Gallesia gorazema), cabreúva (Miroxylon peruiferum), pau-marfim (Balfourodendron riedeliaunu:n), ipê-roxo (Tabebuia avellanedae), jatobá (Hymenaea stiibocarta), louro-pardo (Cordia trichotoma) e ipê-amarelo (T'abebuia rellosoi).

5) Propagação Vegetativa - prioritariamente está se trabalhando com: Pinus patula tecunurnanii, $P$. ellicttii var. elliottii, $P$. taeda e Pinus tropicais.

6) Resinagem - prioritariamente está sc tràcalhando com Pinus caribaea var. bondurensis, $P$. caribaex var. babamensise $P$. elliottii var. elliottii. 
f) Quanto às pesquisas e à produção de sementes pelo Instituto Florestal, também se encontram em expansão tanto as das essências nativas como as das exóticas, $O$ Gráfico 3 dá idéia da sua evoluçáo no período de 1980 a 1989, valendo destacar que sementes de Pinus e Eucalyptus já contam com ganhos genéticos devido ao trabalho de melhoramento.

Por outro lado, o Anexo 14 dá idéia da variedade de espécies produzidas pela Instituiçăo.

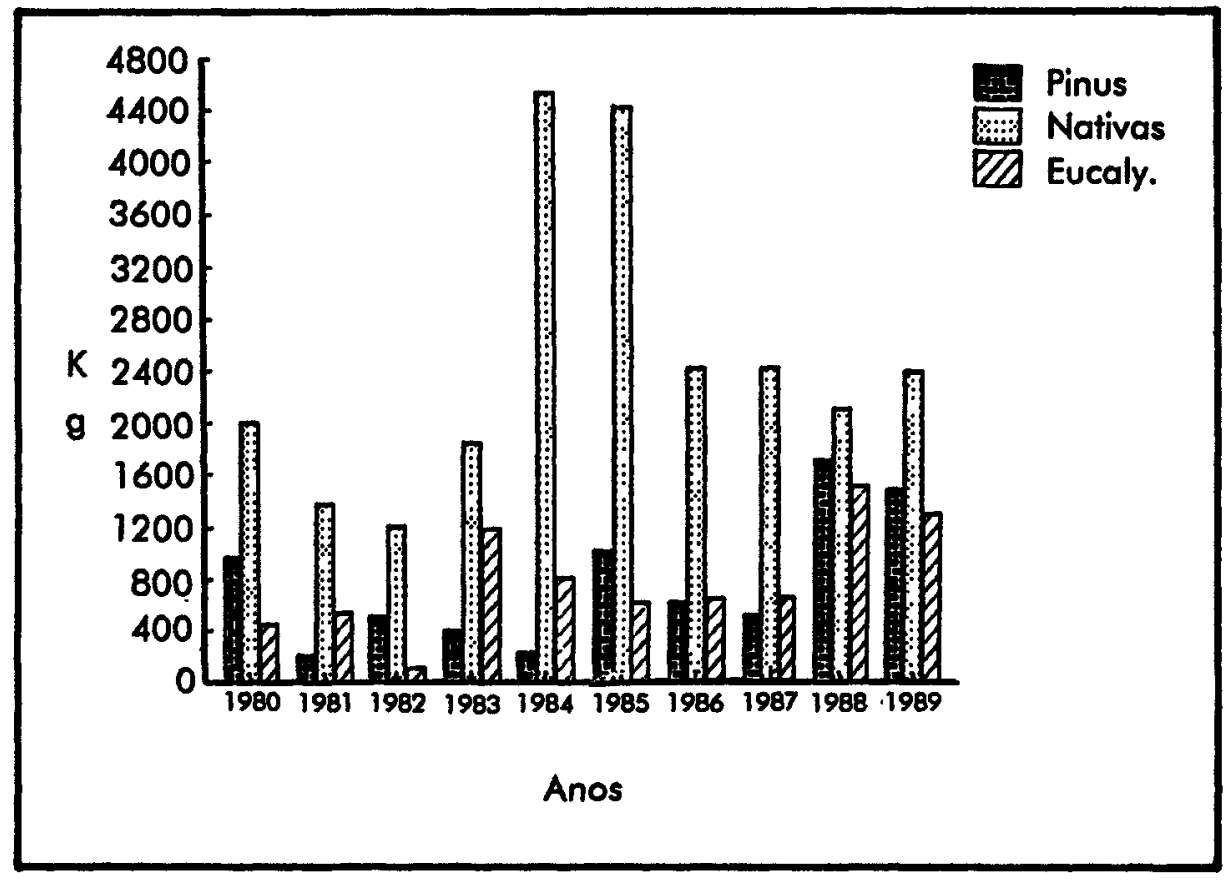

Gráfico 3 - Produçá de sementes de eucaliptos, pinus e de especies nativas (Fonte: Seçäo de Silvicultura. Divisiso de Dasonomia do Instituto Florestal - SP).

g) O "Inventário Florestal", em fase final de execuçăo, tem por objetivos:

- obter a distribuiçáo espacial e a quantificaçáo por área da cobertura vegetal natural e do reflorestamento no Estado;

- mapear e quantificar a cobertura vegetal natural de acordo com os tipos fitofisionômicos (mata, capoeira, cerradáo, cerrado, campo cerrado, várzea, restinga, etc.);

- mapear e quantificar o reflorestamento em termos de área e volume de madeira disponível;

- mapear áreas que devam ser mantidas com características de preservaçáo permanente. 
h) O "Zoneamento Ecológico Florestal", também em execuçăo pelo Instituto Florestal, objetiva:

- estabelecer unidades ecológico-florestais com características de regiōes homogêneas quanto a clima, solo e topografia;

- indicar, por unidade ecológica, espécies florestais e procedências com potencial para serem utilizadas em programas de recomposiçăo de áreas florestais degradadas;

- indicar fontes de abastecimento de sementes, de essências exóticas e nativas, com qualidade reconhecida para atender aos programas anteriormente citados;

- indicar, ao pequeno e médio agricultor, espécies florestais recomendáveis para o suprimento das matérias-primas de uso mais corrente, além de papel e celulose.

i) Com relação ao grave problema das queimadas e dos incêndios florestais, principal chamariz da opinião pública internacional em relaçáo ao Brasil, de modo especial na Amazônia, o Estado de São Paulo mantém hoje o programa "Mata Fogo", envolvendo, além do Instituto Florestal, todos os setores da Defesa Civil do Estado, com a participaçáo da Casa Militar, da CPRN, da CETESB, do DEPRN, da Polícia Florestal e de Mananciais, do Corpo de Bombeiros, das Prefeituras Municipais e das Empresas do Setor Florestal.

Este programa teve origem no Instituto Florestal que, em 1984; iniciou trabalho de polarizaçáo para organizar a comunidade na regiáo de Itapeva e Itararé, de modo especial com a arregimentaçáo dos reflorestadores e dos poderes públicos da regiāo, no que foi também apoiado pela direçáo da FLONA de Capão Bonito.

Esta iniciativa havia evoluído, em 1986, para um trabalho conjunto com a Delegacia do IBDF, Polícia Florestal e de Mananciais, DEPRN, CONSEMA, Associação dos Reflorestadores, entre outros, na tentativa de ampliar este tipo de organizaçăo para todo o Estado. Hoje, nesta ação conjunta, o suporte físico fundamental tem sido a rede de Florestas e Estaçóes Experimentais, Parques Estaduais, Estaçóes Ecológicas e Viveiros Florestais sob administraçāo do Instituto Florestal. $O$ Anexo 15 demonstra este tipo de ação, através dos registros das ocorrências de incêndios atendidas em junho de 1990, o que é possível visualizar através do Gráfico 4, que revela os tipos de percentuais. 
Com o relato apresentado, tivemos a intenção de demonstrar o potencial de nossa Instituição, naquilo que poderia contribuir para o desenvolvimento do Projeto FLORAM, e colocamo-nos à disposiçáo para os esclarecimentos que se fizerem necessários.

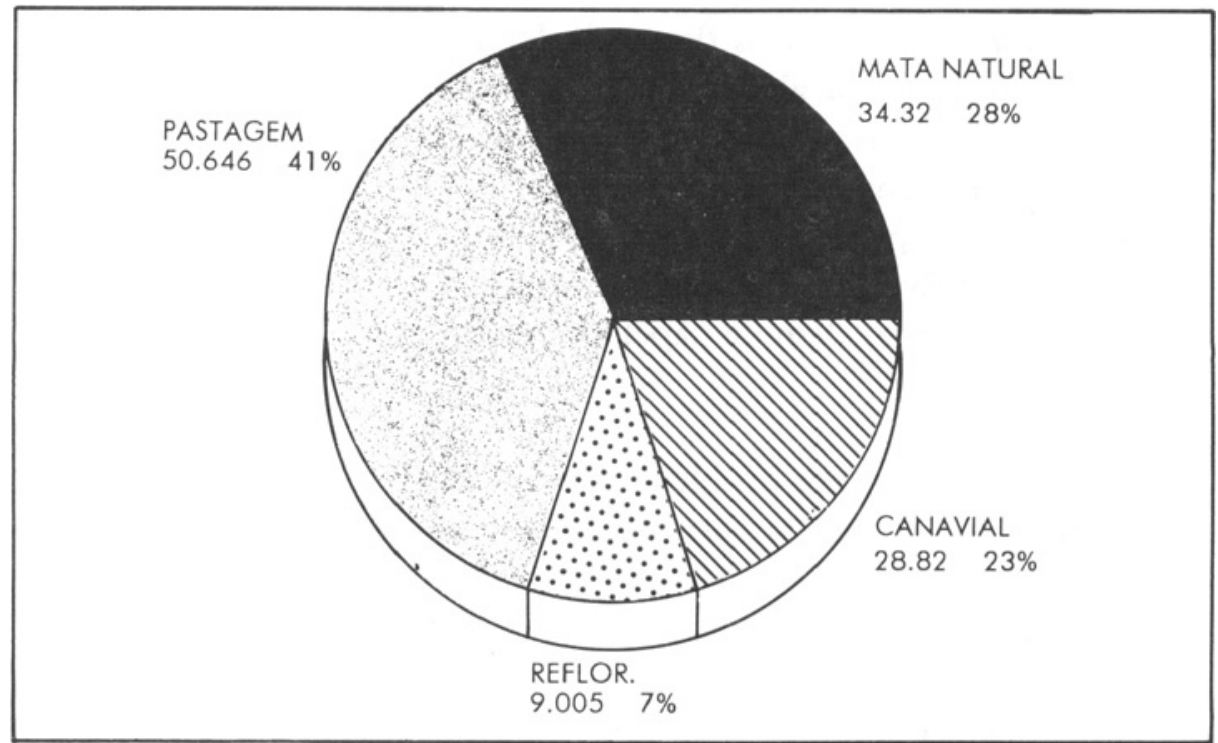

Gráfico 4 - Ocorrência de Incêndio segundo o percentual de vegetação atingido. Período: junho/1990 